\author{
JOURNAL OF INFORMATION \\ SYSTEM AND TECHNOLOGY \\ MANAGEMENT \\ (JISTM) \\ wWw.jistm.com
}

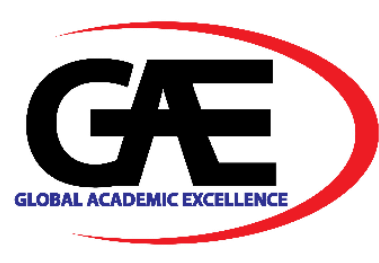

\title{
THE IMPACT OF COVID-19 ON STUDENTS' WILLINGNESS TO COMMUNICATE IN ENGLISH IN HIGHER EDUCATION INSTITUTIONS IN A DIGITAL CONTEXT (HEIs)
}

\author{
Anna Lynn Abu Bakar ${ }^{1}$, Irma Wani Othman ${ }^{2 *}$, Saifulazry Mokhtar ${ }^{3 *}$, Sohaimi Mohd Esa ${ }^{4}$ \\ 1 Centre of The Promotion of Knowledge and Language Learning, Universiti Malaysia Sabah, Malaysia \\ Email: annalynn@ums.edu.my \\ 2 Centre of The Promotion of Knowledge and Language Learning, Universiti Malaysia Sabah, Malaysia \\ Email: irma@ums.edu.my \\ 3 Centre of The Promotion of Knowledge and Language Learning, Universiti Malaysia Sabah, Malaysia \\ Email: saifulazry.mokhtar@ums.edu.my \\ 4 Centre of The Promotion of Knowledge and Language Learning, Universiti Malaysia Sabah, Malaysia \\ Email: msohaimi@ums.edu.my \\ Corresponding Author
}

\section{Article Info:}

Article history:

Received date: 11.09 .2021

Revised date: 10.10 .2021

Accepted date: 15.11 .2021

Published date: 30.11 .2021

\section{To cite this document:}

Abu Bakar, A. L., Othman, I. W., Mokhtar, S., \& Esa, S. M. (2021). The Impact of Covid-19 On Students' Willingness To Communicate In English In Higher Education Institutions In A Digital Context (HEIs). Journal of Information System and Technology Management, 6 (23), 21-33.

DOI: $10.35631 / J I S T M .623002$

This work is licensed under CC BY 4.0

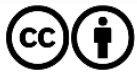

\section{Abstract:}

The outbreak of the Covid-19 Pandemic has brought a shift in the way the teaching and learning process has been conducted in the education field. Most of the lessons are conducted in a digital context for the safety of both teachers and students. Thus, this study aims to look into the impact of the pandemic on students' willingness to communicate (WTC) in English in a digital context in a local higher education institution (HEIs) in Sabah, Malaysia. A qualitative approach was employed in this study involving 25 pre-university students. The data was obtained from a focus group interview and was later transcribed and coded into dominant and sub-dominant themes. The findings revealed that the students unanimously agreed that having classes in a digital context does affect their WTC in English. It is hoped that these findings would give a better insight to English language instructors (ELIs) to plan a conducive learning environment that could facilitate students' WTC in a digital context.

Keywords:

WTC, Pre-University Students, Digital Context, Covid-19, Higher Education Institutions 


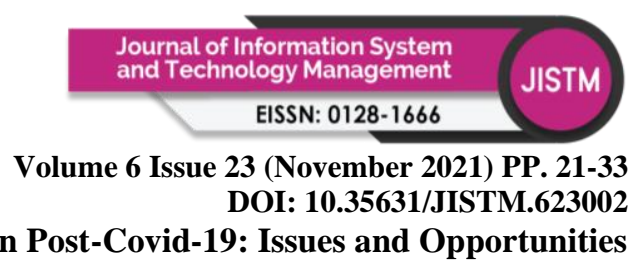

\section{Introduction}

Teachers and students are impacted in a variety of ways during classroom activities as a result of the epidemic era's rapid shift from offline to online learning. Face-to-face instruction is being phased out in favour of online classrooms, in which students learn through a variety of tools and platforms, including group chat, digital classes, and video calls. In this case, teachers must consider both the learning objective and the students' current circumstances when determining the appropriate platforms. Meanwhile, students are being forced to abandon their previous learning habits in real-world activities in favour of virtual ones that allow them to participate in virtual presentations, discussions, and activities. Due to the fact that online classes have altered the classroom environment, students should exhibit a different proclivity for virtual communication during classroom activities. As such, the purpose of this research is to examine students' willingness to communicate (WTC) in a digital context despite the Covid-19 outbreak in Sabah, Malaysia.

The general research objectives of the study are to,

a) discover the challenges faced by pre-university students during online class that affects their WTC in English

b) Identify the solutions taken to overcome the problem.

The research questions of the study are;

a) What are the challenges faced by pre-university students during online class that affects their WTC in English?

b) What are the solutions taken to overcome the problem?

\section{English Language Teaching in Malaysia}

English is widely known as a lingua franca or 'world language' and is widely spoken and written by people across the globe, officially and personally. According to Thirusanku and Md. Yunus (2012) English is an official language in 52 countries and has a wider distribution compared to other spoken languages. Where English is spoken as a second language, English is seen as an important and usually the official language but not the main language of the countries. The example for countries where English is spoken as a second language are India, the Philippines, Nigeria and Malaysia. These countries are ex-colonies of the United Kingdom or the United States.

With regards to Malaysia, the English language has been given the status of a second official language next to Bahasa Melayu which is the official language of the country. However, this is argued by Wahi, O'Neill and Chapman (2011) that English language may not essentially be the second language for Malaysian students as it could be the first, second, foreign or even 'alien' to some students. This is determined by the locality of where the students live. Students from urban area for example have a wider exposure to the language compared to those who are staying in the rural area. They have a wider contact to the English language and may come from homes where English is used, that leads to their competency in communicating in English (Gobel, Thang, Sidhu, Oon, \& Chan,2013). On the other hand, students who live in rural areas, are most likely be using their mother tongue as medium of communication in the houseful. Compared to the students in the urban area, they have minimal or no contact to English outside of school and they are not in the environment where they are able to practice the language learnt in school. This has led to students unwilling to communicate in English as they have few opportunities to use the language. 


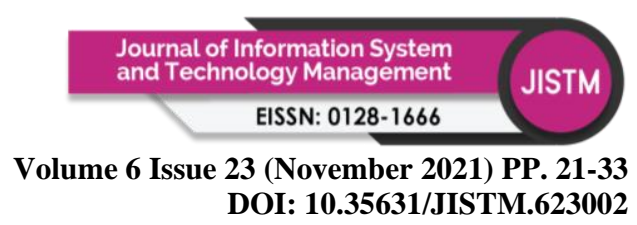

Special Issue: Foundation Program Education Post-Covid-19: Issues and Opportunities However, due to the current pandemic outbreak, educators and students are 'forced' to work and study from home, utilising the digital platform to continue teaching and learning. As a result, educational institutions are increasingly embracing and implementing online learning (Vonderwell \& Zachariah, 2005). Students' WTC in English have been influenced by having classes online. A study conducted in Vietnam (Le et al., 2018) confirms that having classes in a digital context appears to increase students' WTC in English compared to having face-to-face classes.

\section{Social Presence Theory}

Social presence was first conceptualized by Short et al. (1976) and defined as the importance of the interaction partners and their interpersonal relationship during a mediated conversation. According to Short et al. (1976), intimacy and immediacy are the two core components of social presence. These two concepts are closely related. Intimacy refers to the sense of connectedness felt by interlocutors during an interaction, while immediacy refers to the psychological distance between interlocutors. Both intimacy and immediacy are determined by verbal and nonverbal cues such as facial expressions, voice, gestures, and physical appearance (Gunawardena \& Zittle, 1997). Short and colleagues argued that some media are better able to convey these cues while others are not. They emphasized that social presence is a "property of the medium itself" (Short et al., 1976, p. 65).

Short et al. (1976) were the first to describe social presence as the importance of the interaction partners and their interpersonal relationship during a mediated discourse. The two essential components of social presence, according to Short et al. (1976), are intimacy and immediacy. These two ideas are inextricably linked. Interlocutors' feelings of togetherness during a contact are referred to as intimacy, while the psychological distance between them is referred to as immediacy. Both verbal and nonverbal clues, such as facial expressions, voice, gestures, and physical appearance, determine intimacy and immediacy (Gunawardena \& Zittle, 1997). Short and colleagues claimed that some media are better than others at conveying these indications. They stressed the importance of social presence as a "feature of the medium itself" (Short et al., 1976, p. 65).

Online social presence is defined as a degree of feeling connected to, observing, and reacting to another person without being physically present in the same area when it comes to online learning (Kim et.al., 2016; Tu \& McIsaac, 2002). In online education, social presence is especially important since it helps to build a learning environment (Caspi \& Blau, 2008). This is supported by Le et al. (2018), who discovered that social presence has been investigated in the context of online learning. Research studies have shown that there is also a link between students' views of social presence and their perceptions of learning and learner satisfaction, (Richardson \& Swan, 2003; So \& Brush, 2008). This is important because their social presence influences their involvement during class (Le. et. al, 2018). With relation to students WTC in English, the point brought forward by Le et. al (2018) is significant as it would also influence students WTC in English with their peers and lecturers.

\section{Willingness to Communicate L2 Model}

Willingness to communicate (WTC) in a second language (L2) is a theoretical model based on L1 WTC model of McCroskey and Baer (1985) and model describes the mental processes on initiating communication in L2 in a pyramid shape. 


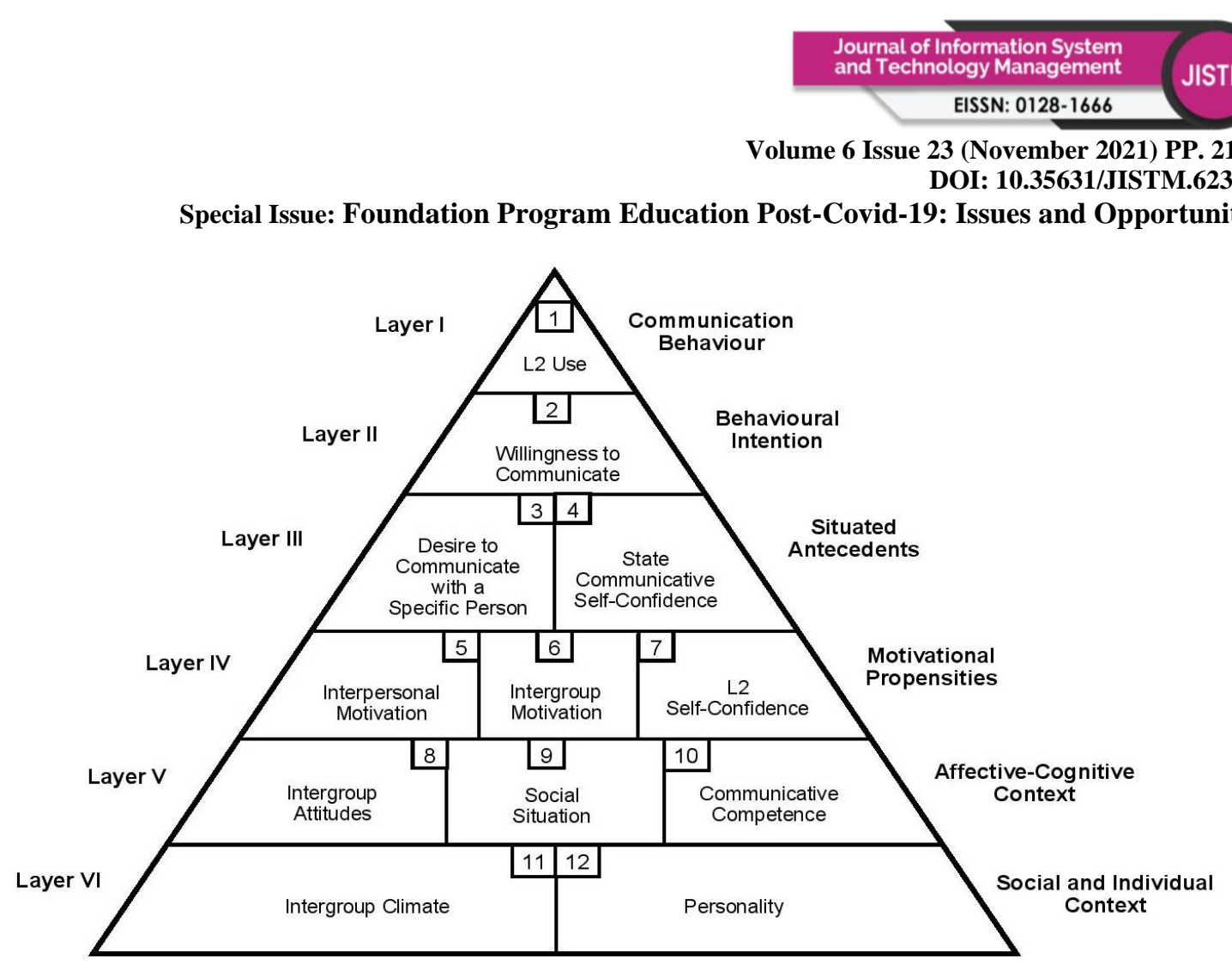

Figure 1: Willingness to Communicate in L2

Source: MacIntyre, Clement, Dornyei, Noels (1998)

MacIntyre proposed in 1994 that future researchers measure WTC by combining personality characteristics with situational data (p. 140). This is due to the fact that these two variables are linked and are determinants of learners' WTC. To this aim, one of the earliest important models of L2 WTC (MacIntyre et al., 1998), which would have a significant impact on second language research, viewed WTC as a combination of "transient and lasting impacts" (p. 546). "A willingness to come into discourse with a certain person or persons at a precise time, utilising an L2" is how L2 WTC is defined (MacIntyre, et al., 1998, p. 547).

MacIntyre et al. are the ones that came up with the idea of WTC (1998). They presented a range of personality, affective, and situational factors that might be included into a six-layer theoretical model, with each layer influencing the usage of the target language. The authors show that both long-term and momentary effects drive communication willingness in this model. According to MacIntyre et al. (1998), a language learner develops more control over the act of communicating in the target language as they progress up the pyramid.

The model by MacIntrye et. al (1998) above illustrates the Willingness to Communicate inside the classroom. The model, with six layers, has a total of twelve constructs (MacIntyre et al. 1998). In the model, MacIntyre et.al (1998) states communication behaviours as the top layer of the model which not only refers to speaking activities, but also to other activities, such as reading newspapers and watching TV in L2.

Behavioural intention in layer II refers to Willingness to Communicate. This means that, whether the student is willing to communicate with other people using L2 as medium of communication. 


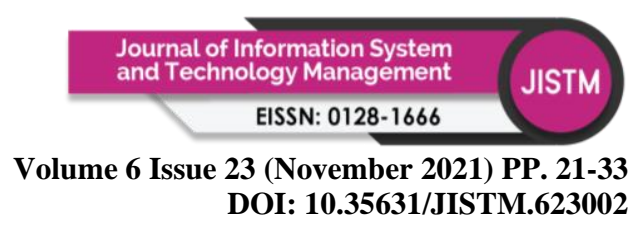

Special Issue: Foundation Program Education Post-Covid-19: Issues and Opportunities Apart from that, the variable in Layer III indicates situated antecedents which immediately influence the WTC which consist of Desire to Communicate with a Specific Person as well as State Communicative Self-Confidence.

Pattapong (2013) mentions that the Desire to Communicate with a Specific Person depends on situations where two types of motives operate. These motives are Affiliation and Control. Affiliation refers to a need to establish a relationship with the speakers that comes from integrative motives such as attractiveness, similarity, and familiarity, while Control refers to a type of communication which depends on instrumental motives, such as more powerful speakers, with the aim to manipulate each other when communicating by requiring their assistance, cooperation or services.

State Communicative Self- Confidence is determined by State Anxiety and State Perceived Competence. While State Anxiety refers to levels of worry in speaking in a specific situation, which can be influenced by many factors, such as negative past experiences, State Perceived Competence refers to how a person perceives their capacity to communicate at the moment of speaking. These two situationally dependent variables are the most prominent determinants of WTC as identified by MacIntyre (1994), MacIntyre \& Charos (1996) which are the most significant antecedents of WTC as confirmed by McCroskey and Richmond (1997,2007).

In Layer IV, MacINtyre et. al (1998) state that Motivational Propensities. MacIntrye (1998) describes this as consistent individual traits presented in many situations. This layer contains three variables. The first variable is, Interpersonal Motivation which is determined by either Control or Affiliation. The next variable is, Inter-group Motivation which is directly affected by a particular group to which a person belongs and which is impacted by Intergroup Climate and Intergroup Attitudes in layers below and also depends on either Control or Affiliation. The last variable is L2 Self-Confidence which consists of two components, Cognitive and Affective. The L2 self-confidence at this level is more stable than state communicative selfconfidence in the situational level.

Layer V, Affective-Cognitive Context in the WTC model includes three variables which are Intergroup Attitudes, Social Situation, and Communicative Competence. With regards to Intergroup Attitude, Gardner (1985) mentions that in order to learn L2, the speaker will mix and identify with other members of the L2 community. On the other hand, feeling anxious to assimilate and losing identity would be a strong reason to void from learning and applying the L2. (Clement \& Krudenier, 1985).

As for Social Situation, one's experience in a social situation may result to positive or negative influence of one's WTC in the L2. Positive experience results to increasing one's confidence in initiating a conversation in the target language whereas negative experience may hinder one to WTC in the target language. Communicative Competence refers to the speaker's grammatical and social knowledge and skill on how and when to use utterances appropriately.

Lastly, layer VI of the model, Social and Individual Context, comprises of two variables which are, Intergroup Climate and Personality. Intergroup Climate reflects the special characteristics of the bilingual context, where the issue of availability of the language or linguistic vitality (Structural characteristics of the community), as well as attitudes towards ethnic groups (Perceptual and affective correlates), becomes important. Kogila (2018) mentions that this layer has the most significant because it shows the communication between the individual and Copyright $\odot$ GLOBAL ACADEMIC EXCELLENCE (M) SDN BHD - All rights reserved 


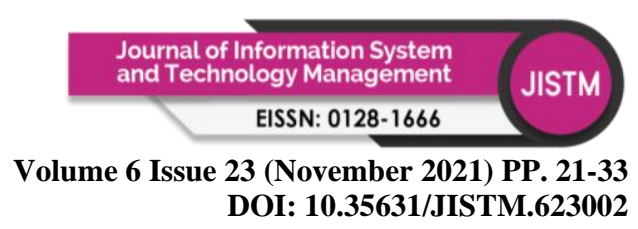

Special Issue: Foundation Program Education Post-Covid-19: Issues and Opportunities the society. This is further supported by Clement and Kruidenier (1985) as he commented that the opportunity to apply the L2 can be achieved through societal context. With relation to intergroup climate, Gardner and Clement (1990) mention that comprehensive intergroup relations promote learning of $\mathrm{L} 2$ whereas inferior intergroup relation may affect the motivation to learn and communicate in the L2. In terms of personality, the speakers' natural characteristics whether one is introvert or extrovert, can determine the degree of L2 learning and their WTC in the target language (MacIntrye \& Charos, 1996)

Another aspect that helps to explain how people react to and communicate with members of their own cultural group as well as out-group members is their personality. Some personality factors that influence second language learning and desire to speak in that second language include extraversion, agreeableness, conscientiousness, emotional stability, and openness to experience (MacIntyre \& Charos, 1996; Lalonde \& Gardner, 1984). Ehrman and Oxford (1990) add to this by stating that various personalities may have varying amounts of willingness to learn a second language, as well as variable levels of competency and/or conscientiousness.

\section{Methodology}

A qualitative approach was used in this study to discover students' WTC in English in a digital context at a local Higher Education Institution in Sabah, Malaysia. The study included 25 participants; whose identities were classified in order to protect their confidentiality.

To collect the empirical data, a semi-structured interview method was used, allowing the researcher to obtain more in-depth information that corresponded with the study's objective. According to Creswell (2014), a semi-structured interview allows the researcher to delve into the feedback provided by the participants, as well as provide specific feedback from the participants. The interview was conducted online using Google Meet as the platform for interview. The questions of the semi-structed interview was adapted from Saidi (2018) on students' WTC.

The procedure for data analysis that follows begins with inductive analysis of audio recordings of interviews with respondents that have been transcribed into text form. Thematic categorisation was performed on each respondent's transcription using coding that resulted in the emergence of specific themes. The researcher obtained the main themes and supporting themes presented by the participants at the end of the process.

Table 1 below shows the demographic profile of the participants involved in the study. A total of 10 participants were involved in the semi-structured interview, where a total of 4 of the participants were male and 6 of the participants were female. 3 of the participants scored $\mathrm{A}+$, 2 scored A, 1 scored A-, 2 of the participants scored B+ and 2 of the participants scored B for their English subject. 
Volume 6 Issue 23 (November 2021) PP. 21-33 DOI: 10.35631/JISTM.623002

Special Issue: Foundation Program Education Post-Covid-19: Issues and Opportunities Table 1: Demographic Profile of Participants

\begin{tabular}{lcc}
\hline Variable & Frequency & $\begin{array}{c}\text { Percentage } \\
(\boldsymbol{\%})\end{array}$ \\
Gender & & \\
$\quad$ Male & 4 & 40 \\
Female & 6 & 60 \\
\hline SPM Results & & \\
A+ & 3 & 30 \\
A & 2 & 20 \\
A- & 1 & 10 \\
B+ & 2 & 20 \\
B & 2 & 20 \\
\hline
\end{tabular}

\section{Findings and Discussion}

The study's findings contributed to empirical data on students' WTC in English in a digital classroom by discussing the solutions and challenges that students faced in an ESL digital classroom during the outbreak of the Covid-19 pandemic that may have hampered their WTC in English. The semi-structured interview data revealed two dominant themes: (a) the challenges of WTC in English in an ESL digital classroom and (b) the solutions used to overcome those challenges.

\section{Challenges in Students' WTC in English in A Digital Context}

Under the theme challenges of WTC in English in an ESL digital classroom, the researcher has identified 3 sub themes which are (i) which are lack of opportunity to communicate in English and (ii) lack of motivation. Figure 1 below further illustrates the sub themes mentioned.

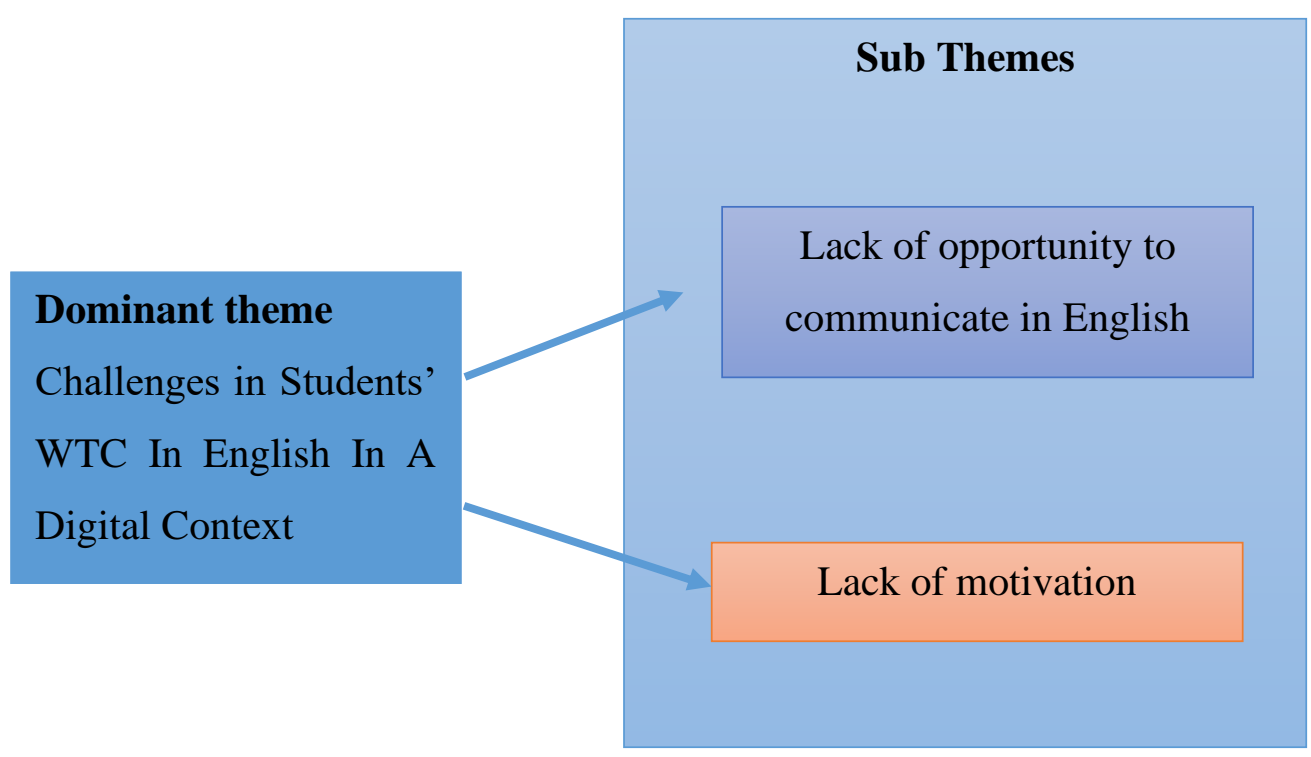

Figure 1: Challenges in Students' WTC in English in A Digital Context 


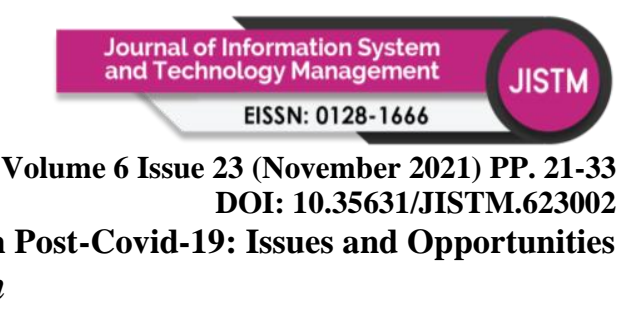

The findings indicated that out of the 10 participants interviewed, 9 agreed that one of the challenges they face when learning in a digital environment is the lack of opportunities to communicate in English with not only their friends, but also with other people.

Table 2: Lack of Opportunity to Communicate in English

\begin{tabular}{cl}
\hline Participant & \multicolumn{1}{c}{ Excerpts } \\
\hline 2 & I lost the opportunity to communicate in English. This is because the \\
& session was not conducted face to face. \\
I do find myself talking less during online classes in comparison to & physical classes \\
& For my family and I, we would communicate using Malay language \\
& rather than the English language. Thus, I have not been speaking \\
& English for a while and due to this, I became more comfortable with \\
& Malay language and find it hard to start speaking English again. \\
& The pandemic definitely affected my willingness to communicate in \\
& English during online class, mainly because of the lack of interaction \\
& as compared to physical classes. \\
& Not able to meet people to practice the language \\
& During online classes, not only do I feel reluctant to turn on my web \\
& cam but the amount of chances to speak up during the class with my \\
& tutor mates are almost none. Thus, communicating verbally or \\
through chat is almost impossible to me. \\
I cannot see others' expression when I'm speaking or presenting and \\
I'm afraid that I made a lot of mistakes with the grammar or \\
vocabulary for example. \\
During online classes, we just sat in chairs, looked at laptop screens \\
and focused on lectures. So, there is no opportunity for us to \\
communicate with other students and hear others talk to their friends \\
like we go to class.
\end{tabular}

Table 2 above show some narrative excerpts taken from the interview regarding their lack of opportunity to communicate in English. Based from the excerpts above, it could be seen that the participants (as stated by participant 2, 4 and 5) prefer to communicate in English face to face rather than via an online platform. However, as the mode of teaching and learning has shifted, the opportunities for practising the English language in a real-world setting have reduced. Not able to see each other face-to-face has also affect their WTC in English as they are not able to see other people's reaction when they are speaking or presenting. (as stated by participant 8 ). This is because during lesson, the students are not made compulsory to turn own their webcam (as stated by participant 7). As a result, this has had an effect on their WTC in English.

\section{Lack of Motivation and Social Presence}

According to the findings of the semi-structured interview, it was discovered that students' WTC in English was also influenced by their level of motivation in the classroom setting. The lack of interaction with other people as a result of the fact that classes are held at home means that most participants feel cut off from the outside world because they are unable to socialise with their peers. They have become lonely and bored as a result of spending the majority of 


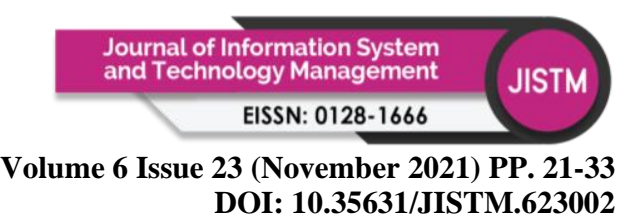

Special Issue: Foundation Program Education Post-Covid-19: Issues and Opportunities their time at home, which has negatively impacted their motivation to learn. Their classmates are also unfamiliar to them due to the fact that their classes have been conducted online since the beginning of the semester of their course, which has prevented them from becoming acquainted with their classmates on a more personal level. Their motivation has also been hampered by the fact that they do not understand what has been taught online as opposed to in a physical face-to-face class environment. In terms of their social presence, students would only be 'present' actively if their names were called upon by their lecturer to answer a specific question on a specific topic (as stated by participant 1). Because they do not know each other, there may also be a lack of social presence on the part of the students (as stated by participant 7). Because they may be concerned about being judged by their peers, they may find it difficult to speak up during class. Their social presence during online class was also affected by the distractions that they face at home that may hamper their focus and concentration in class. The table below show some narrative excerpts taken from the interview with relation to lack of motivation and social presence.

Table 3: Lack of Motivation and Social Presence

\begin{tabular}{cl}
\hline Participant & \multicolumn{1}{c}{ Excerpts } \\
\hline 1 & $\begin{array}{l}\text { I usually remain quiet and just watch everything go on, leaning more } \\
\text { to only being able to speak up when my name is being called upon for } \\
\text { an attendance check or to answer a specific question } \\
\text { Most likely that me and my tutor mates have never met face to face } \\
\text { due to quarantine. So it's difficult to start knowing each other } \\
\text { online classes make me not motivated to join the learning session. } \\
\text { This is because the session was not conducted face to face. Sometimes, } \\
\text { it makes me not attracted to the learning session and makes me not } \\
\text { participate in the class. } \\
\text { Due to distractions at home, I am quite unwilling to ask any questions } \\
\text { that I am unclear of as I am afraid to be a nuisance to my other } \\
\text { classmates. } \\
\text { I had less opportunity to socialize with other students making my } \\
\text { English less utilized as our microphones and cameras shut }\end{array}$ \\
\end{tabular}

\section{Solutions Used to Overcome Challenges}

Another major theme that emerged from the interview was the solutions used to overcome the challenges that the participants faced that could have an impact on their WTC in English in a digital setting. This has resulted in two sub-themes: (i) self-motivation to improve English. (2) Communicate in English with family and friends. Figure 2 depicts the sub-themes mentioned above in greater detail. 


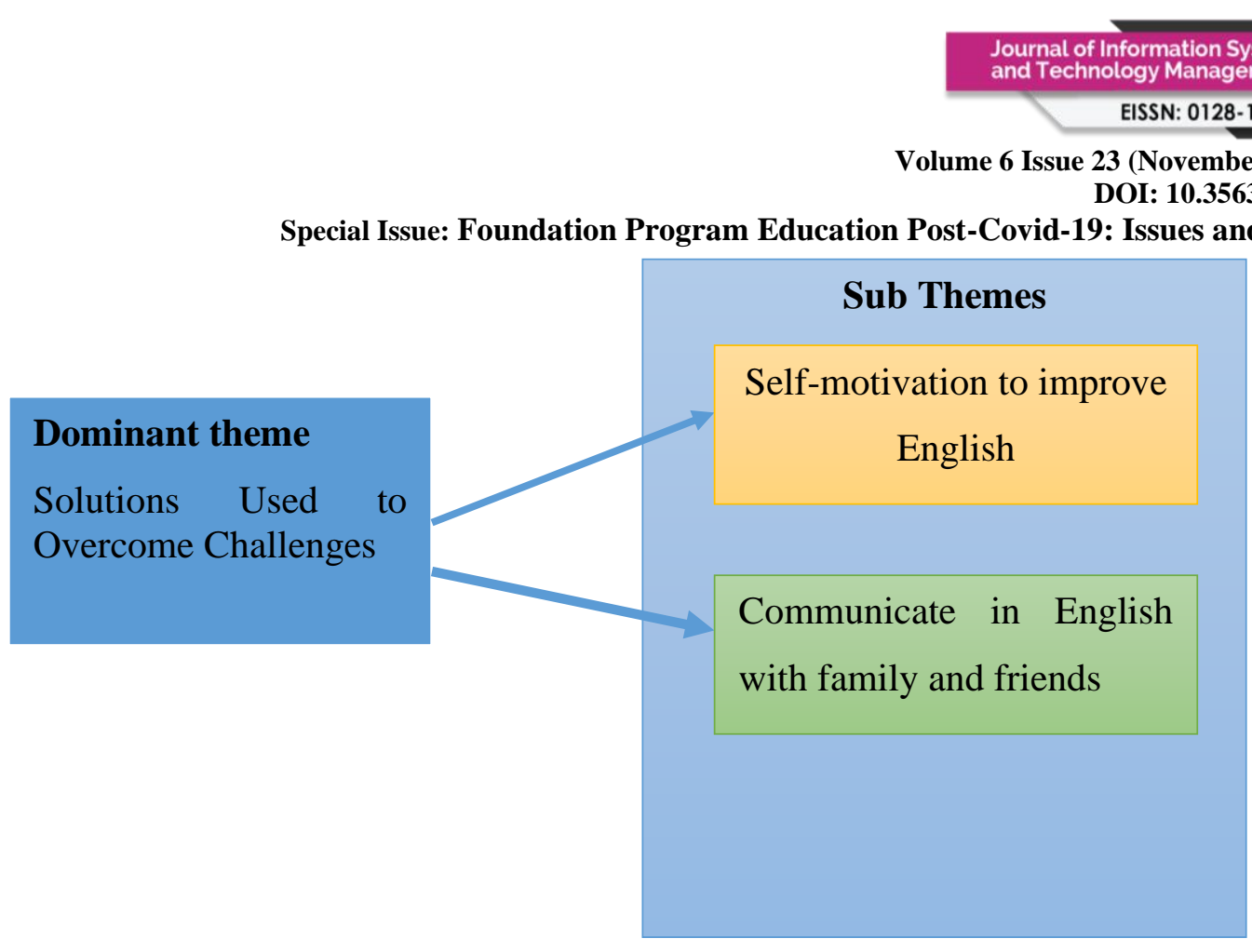

\section{Figure 2: Solutions Used to Overcome Challenges}

\section{Self-Motivation to Improve English}

A solution exists for every problem and can be found at any point in time. Following the interview, it was discovered that, despite having difficulties attending classes online, which has had an impact on their WTC in English when communicating online, the participants stated that they have been able to overcome the obstacles by figuring out how to get themselves back on track while still maintaining their ability to communicate effectively in English. According to participant 3, 8, and 9, some of the steps taken include reading English books, seeking help from friends when needed in terms of grammar, vocabulary and pronunciation as mentioned by participant 2 , preparing for class in order to get into the mood as mentioned by participant 4, and listening to English songs. The steps taken by the participants to self-motivate themselves in order to improve their English are illustrated in the table that follows.

Table 4: Self-Motivation to Improve English

\begin{tabular}{|c|c|}
\hline Participant & Excerpts \\
\hline 3 & $\begin{array}{l}\text { I had started reading again to enhance my English skills. Whenever I } \\
\text { encounter difficult vocabulary, I would Google the meaning so I can } \\
\text { increase my vocabulary knowledge. In the end, I was able to overcome } \\
\text { my problem in communicating in English during online class. }\end{array}$ \\
\hline 2 & $\begin{array}{l}\text { I refer to my friends by asking for help to see if my grammar and } \\
\text { vocabulary were correct and I practice a lot so that my pronunciation } \\
\text { is also correct. I also read a lot of English novels to improve my } \\
\text { English. }\end{array}$ \\
\hline 4 & $\begin{array}{l}\text { the way I handle it is to always prepare before the class starts. If the } \\
\text { class was in the morning, I will make sure I take a bath and breakfast } \\
\text { first. I also prepare the material for the class }\end{array}$ \\
\hline 9 & $\begin{array}{l}\text { To overcome this problem, I took the time to listen to English music } \\
\text { and read articles and notes in English until I became accustomed to } \\
\text { English. }\end{array}$ \\
\hline
\end{tabular}




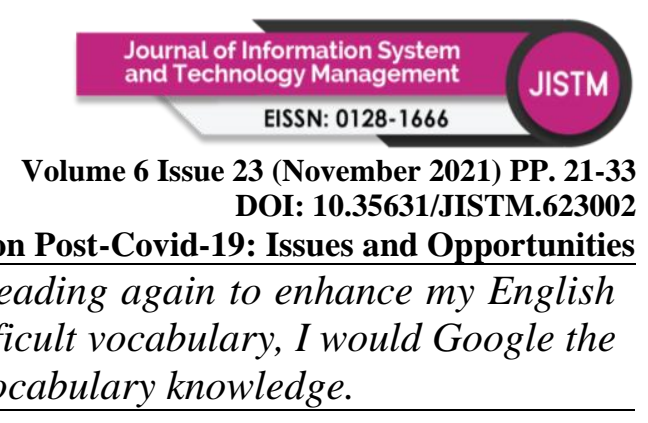

\section{Communicate in English with Family and Friends}

Communicating English with family and friends is another subtheme identified to improve students' WTC. Because the students have indicated that they lack opportunities to communicate in English due to the constraints that they face during online class, they have taken the initiative to communicate in English with their family members as well as make the effort to get to know their classmates in order to break the ice and feel more comfortable communicating with them. Participant 8 stated, for example, that she would video call her friends and communicate with them in English. In contrast to participant 5, who stated that speaking to lecturers in practise is more effective because English would have to be used out of formality.

\section{Table 5: Communicate in English with Family and Friends}

\begin{tabular}{cl}
\hline Participant & Excerpts \\
\hline 1 & $\begin{array}{l}\text { English has been a loved language to me since I was little and I have } \\
\text { practiced it with my family and friends from time to time, } \\
\text { I've made effort in befriending others to better understand them and } \\
\text { have a sense of comfort with their presence. } \\
\text { Sometimes I speak in English with my relatives. }\end{array}$ \\
8 & $\begin{array}{l}\text { I would video call my friends and communicate with them in English. } \\
\text { I find English communication to be more utilized when } \\
\text { communicating with lecturers out of formality. I think the approach } \\
\text { to overcoming this is just by contacting the lecturers more often to } \\
\text { build up the courage to communicate in English. }\end{array}$ \\
\hline
\end{tabular}

\section{Conclusion}

The study's findings revealed that having classes in a digital setting has had a significant impact on students, which may influence their WTC in English. The interview findings revealed two major challenges that students faced in a digital context: a lack of opportunities to communicate English with other people, and a lack of motivation and social presence during class. Aside from that, the study's findings have also highlighted the solutions used by students to overcome their ordeal in their WTC in English in a digital setting. Students' self-motivation in improving their English, which includes reading English books, listening to English songs, and watching English movies, was one of the two main solutions implemented. Aside from that, another solution was to practise communicating in English with family and friends. Despite having to take classes online, these solutions are hoped to assist them in overcoming their difficulties and improving their WTC in English.

\section{References}

Caspi, A., \& Blau, I. (2008). Social presence in online discussion groups: Testing three conceptions and their relations to perceived learning. Social Psychology of Education: An International Journal, 11(3), 323-346.

Clément, R., \& Kruidenier, B. G. (1985). Aptitude, attitude and motivation in second language proficiency: A test of Clément's model. Journal of Language and Social Psychology, 4(1), 21-37. https://doi.org/10.1177/0261927X8500400102 


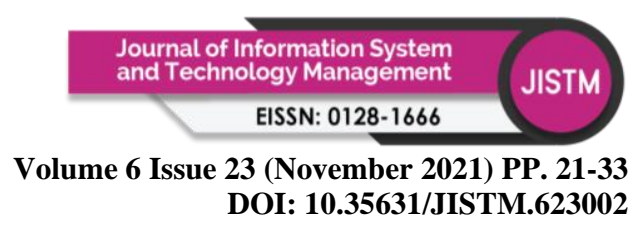

Special Issue: Foundation Program Education Post-Covid-19: Issues and Opportunities

Creswell, J. (2014). Research Design (4th ed). Lincoln: SAGE Publications, Inc.

Ehrman, M. and Oxford, R. (1990). Adult Language Learning Styles and Strategies in An Intensive Training Setting. The Modern Language Journal, 74(3), 311-327

Gardner, R. C., \& Clément, R. (1990). Social psychological perspectives on second language acquisition. In H. Giles \& W. P. Robinson (Eds.), Handbook of language and social psychology (pp. 495-517). John Wiley \& Sons.

Gobel, P., Thang, S. M., Sidhu, G. K., Oon, S. I., \& Chan, Y. F. (2013). Attributions to success and failure in English language learning: A comparative study of urban and rural undergraduates in Malaysia. Asian Social Science, 9(2), 53-62. https://doi.org/10.5539/ass.v9n2p53

Gunawardena, C. N., and Zittle, F. J. (1997). Social presence as a predictor of satisfaction within a computer-mediated conferencing environment. American. Journal Distance Education. 11, 8-26. doi: 10.1080/08923649709526970

Kim, J., Song, H., \& Luo, W. (2016). Broadening the understanding of social presence: Implications and contributions to the mediated communication and online education. Computers in Human Behavior, 65, 672-679.

Kogila, C.S. (2018). Relationship between learners' variables and students' Willingness to communicate in the classroom. Unpublished Ph. D. thesis

Lalonde, R. N., \& Gardner, R. C. (1984). Investigating a causal model of second language acquisition: Where does personality fit? Canadian Journal of Behavioural Science / Revue canadienne des sciences $d u$ comportement, 16(3), 224237. https://doi.org/10.1037/h0080844

Le, T.V., Cunningham, U., Watson, K. (2018). The relationship between Willingness to Communicate and social presence in and online English language course. JALT CALL Journal. 14 (1). 43-59.

MacIntyre, P. D., Dornyei, Z., Clement, R., \& Noels, K. A. (1998). Conceptualizing willingness to communicate in a L2: A situational model of L2 confidence and affiliation. The Modern Language Journal, 82(4), 545e562.https://doi.org/10.1111/j.1540-4781.1998

MacIntyre, P. D., \& Charos, C. (1996). Personality, attitudes, and affect as predictors of second language communication. Journal of Language and Social Psychology, 15(1).

Patapong, K. (2013). Willingness to communicate in a second language: A qualitative study of issues affecting Thai EFL learners from students' and teachers' points of view. Unpublished Ph. D. thesis

Richardson, J., \& Swan, K. (2003). Examining social presence in online courses in relation to students' perceived learning and satisfaction. Journal of Asynchronous Language Networks, 7(1), 68-88.

Short, J., Williams, E., and Christie, B. (1976). The Social Psychology of Telecommunications. New York, NY: John Wiley.

So, H.J. \& Brush, T. A. (2008). Student perceptions of collaborative learning, social presence and satisfaction in a blended learning environment: Relationships and critical factors. Computers \& Education 51,318-336.

Thirusanku, J. \& Yunus, M.M. (2012). The Many Faces of Malaysian English. International Scholarly Research Network. 12. 1-14

Tu. C. H., \& McIsaac, M. (2002). The relationship of social presence and interaction in online classes. The American Journal of Distance Education, 16(3),131-150.

Vonderwell, S. \& Zachariah, S. (2005). Factors that Influence Participation in Online Learning. Journal of Research on Technology in Education. 38 (2), 213 - 230.

Copyright $\odot$ GLOBAL ACADEMIC EXCELLENCE (M) SDN BHD - All rights reserved 
Volume 6 Issue 23 (November 2021) PP. 21-33 DOI: 10.35631/JISTM.623002

Special Issue: Foundation Program Education Post-Covid-19: Issues and Opportunities

Wahi, W., O’Neill, M., \& Chapman, A. (2011). Investigating English language academic literacy for employability of undergraduate students: A case in a Malaysian public university. In A. Pandian, M. Ismai, \& C. Toh (Eds.), Teaching and learning in diverse contexts: Issues and approaches. 90-101). Malaysia: School of Languages, Literacies and Translation, USM 